\title{
Tetrahedron Letters
}

journal homepage: www.elsevier.com/locate/tetlet

\section{A dramatic effect of double bond configuration in N-oxy-3-aza Cope Rearrangements: a simple synthesis of functionalised allenes}

Luis F. V. Pinto a, Paulo M. C. Glória a, Mário J. S. Gomes a, Henry S. Rzepa b, Sundaresan Prabhakar a, ${ }^{*}$, Ana M. Lobo a, ${ }^{*}$

a Chemistry Department, REQUIMTE/CQFB, Faculty of Sciences and Technology, New University of Lisbon, and SINTOR-UNINOVA, 2829-516 Monte de Caparica, Portugal

b Chemistry Department, Imperial College London, South Kensington Campus, SW7 2AY London, UK

Article history:

Received 24 February 2009

Accepted 25 February 2009

Available online 14 March 2009

ABSTRACT

The first examples of low temperature $\mathrm{N}$-oxy-3-aza Cope rearrangements, leading to functionalized allenes are described, where the Z-configuration of the enaminic double bond in the rearranging system proves critical.

\section{KEYWORDS}

3-Aza Cope rearrangements

Hydroxylamines

Enamines

Allenes

Configuration

Intermediates

Transition states

2009 Elsevier Ltd. All rights reserved. 